\title{
THE REASONS ACUTE STROKE PATIENTS NOT RECEIVING THROMBOLYSIS IN AN INDONESIAN REFERRAL HOSPITAL
}

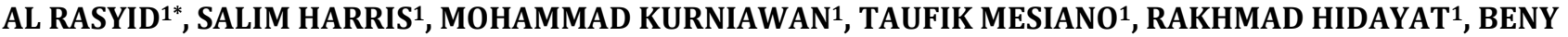 RILIANTO' ${ }^{1}$, RATU AZIZAH SHOLEHA ${ }^{2}$}

1Department of Neurology, Faculty of Medicine, University of Indonesia/Cipto Mangunkusumo Hospital, Jakarta 10430, Indonesia, ${ }^{2}$ Faculty of Medicine, University of Indonesia, Jakarta 10430, Indonesia

Email: alrasyid50@yahoo.com

Received: 16 Aug 2019, Revised and Accepted: 16 Oct 2019

\section{ABSTRACT}

Objective: The aim of this study was to identify reasons acute stroke patients did not receive thrombolysis despite meeting Code Stroke activation criteria in Cipto Mangunkusumo General Hospital during November 2015 until February 2019.

Methods: This study retrospectively collected data of adult (aged $>18$ y old) acute stroke patients admitted to Cipto Mangunkusumo General Hospital from November 2015 to February 2019 who met criteria for Code Stroke activation but did not undergo thrombolysis. Patient' data were collected from Code Stroke Registry of Cipto Mangunkusumo General Hospital.

Results: There were 518 acute stroke patients who had Code Stroke activated in Cipto Mangunkusumo General Hospital from November 2015 to February $2019.76 .3 \%$ of acute stroke patients did not receive thrombolytic therapy $(n=395)$. Hemorrhage on computed tomography (CT) scan was the most common reason patients did not receive thrombolysis. The following most common reasons were low or improved National Institutes of Health Stroke Scale (NIHSS) score, family refusal, and exceedance of time window.

Conclusion: Hemorrhage on CT scan was the most common reason patients did not receive thrombolysis following by low or improved NIHSS score, family refusal, and exceedance of time window.

Keywords: Stroke, Thrombolysis, Code Stroke, Indonesia

(C) 2019 The Authors. Published by Innovare Academic Sciences Pvt Ltd. This is an open-access article under the CC BY license (http://creativecommons.org/licenses/by/4.0/D DOI: http://dx.doi.org/10.22159/ijpps.2019v11i11.35373

\section{INTRODUCTION}

Stroke can be caused either by ischemia or hemorrhage. Ischemic stroke holds accounts for $67 \%$ of stroke patients while hemorrhagic stroke holds the rest (33\%) [1]. Despite having a smaller prevalence, hemorrhagic stroke had higher mortality than ischemic stroke. Yudiarto et al. study found there were $18.3 \%$ deaths of hemorrhagic stroke patient's $\leq 48 \mathrm{~h}$ of onset while there were $3.5 \%$ deaths of ischemic stroke patients [2].

Code Stroke is a fast response effort to handle stroke time-efficiently in order to provide on-time thrombolysis for acute ischemic stroke patients to minimize obstacles causing delayed intervention. In Cipto Mangunkusumo General Hospital, Code Stroke can be activated with onset-to-door time up to $6 \mathrm{~h}$. The purpose of this regulation is to gain the best benefits of thrombolysis with the longest onset-to-treatment time allowed. The door-to-needle time is based on the National Institutes of Health (NIH) recommendation, which is $60 \mathrm{~min}$ [3]

Despite meeting the eligibility criteria for Code Stroke activation, not all patients receive thrombolysis. Messé et al. study found that about onequarter of acute ischemic stroke patients in United States failed to have thrombolysis performed [4]. Chinese National Stroke Registry data showed that only $181(12.3 \%)$ of 1469 eligible acute ischemic stroke patients received thrombolysis [5]. There is not much study yet identifying reasons for eligible stroke patient not receiving thrombolysis. In Indonesia, there is no published study on that area yet.

The aim of this study was to investigate reasons acute stroke patient not receiving thrombolysis despite meeting Code Stroke activation criteria in Cipto Mangunkusumo General Hospital.

\section{MATERIALS AND METHODS}

\section{Subjects and procedures}

This study retrospectively collected data of acute stroke patients admitted to Cipto Mangunkusumo General Hospital from November
2015 to February 2019. Subjects of this study were adult (aged>18 y old) acute stroke patients who met criteria for Code Stroke activation but did not undergo thrombolytic therapy.

Collected patients' data including sex, age, National Institutes of Health Stroke Scale (NIHSS) score on arrival, time of symptom onset to hospital arrival (onset-to-door time), chief complaint, and reason why thrombolytic therapy did not performed on the patient. Data were collected from Code Stroke Registry of Cipto Mangunkusumo General Hospital. Identity and data of all patients were held confidential.

\section{Statistical analysis}

Data were analyzed statistically using SPSS version 20 . Numerical data were presented as means and standard deviation if normally distributed ( $p>0.05)$, and as median and range if not normally distributed. Normality of numerical data was tested using Kolmogorov-Smirnov normality test due to the number of subject $>50$. Categorical data were presented as frequencies and percentages.

\section{RESULTS}

There were 518 acute stroke patients who had Code Stroke activated in Cipto Mangunkusumo General Hospital from November 2015 to February 2019. This number included any type of stroke, whether it was ischemic or hemorrhagic.

There were more than three quarters of acute stroke patients who did not receive thrombolytic therapy $(76.3 \%, n=395)$. Most of those patients were male (60.5\%). Median age of the patients was $56 \mathrm{y}$ old. Median onset-to-door time was 175 min. Median National Institutes of Health Stroke Scale (NIHSS) score of the patients on arrival was 10. Loss of consciousness became the most common chief complain (37.5\%), followed by right-sided weakness and left-sided weakness (each, 20.8\%). Baseline demographic and clinical characteristics of patients were described in table 1 . 
Table 1: Baseline demographic and clinical characteristics of patients

\begin{tabular}{lll}
\hline & $\mathbf{n = 3 9 5}$ & $\mathbf{\%}$ \\
\hline Demographic & $56.00(55.05-57.46)$ & 39.5 \\
Age, y* & 156 & \\
Sex (female) & $175(161-183)$ & \\
Clinical & $10(9-11)$ & \\
Onset-to-door, min & & 37.5 \\
Initial NIHSS score* & 148 & 20.8 \\
Chief complain & 82 & 20.8 \\
Loss of consciousness & 82 & 6.1 \\
Left sided weakness & 24 & 3.3 \\
Right sided weakness & 13 & 2.8 \\
Dysarthria & 11 & 2.0 \\
Dizziness/vertigo & 8 & 2.0 \\
Aphasia & 8 & 1.0 \\
Left sided numbness & 4 & 0.8 \\
Seizure & 3 & 0.8 \\
Hemifacial weakness & 3 & 0.8 \\
Right sided numbness & 3 & 0.3 \\
Visual loss & 1 & \\
Headache & & \\
Memory loss & 3 & \\
\hline
\end{tabular}

Data are presented as $\mathrm{n}(\%)$ for categorical variables and as median (interquartile range) for numerical variables. NIHSS: National Institutes of Health Stroke Scale, *Kolmogorov-Smirnov normality test $<0.05$.

\section{Reasons acute stroke patients did not receive thrombolytic therapy}

Hemorrhage on computed tomography (CT) scan became the most common reason patients did not receive thrombolysis (42.3\%). Low or improved NIHSS score was the second most common reason, with percentage $22.8 \%$. There were $7.8 \%$ of patients who did not receive thrombolytic therapy due to family refusal. Exceedance of the time window became the fourth most common reason (4.1\%). Another reasons acute stroke patients did not receive thrombolysis could be seen in fig. 1.

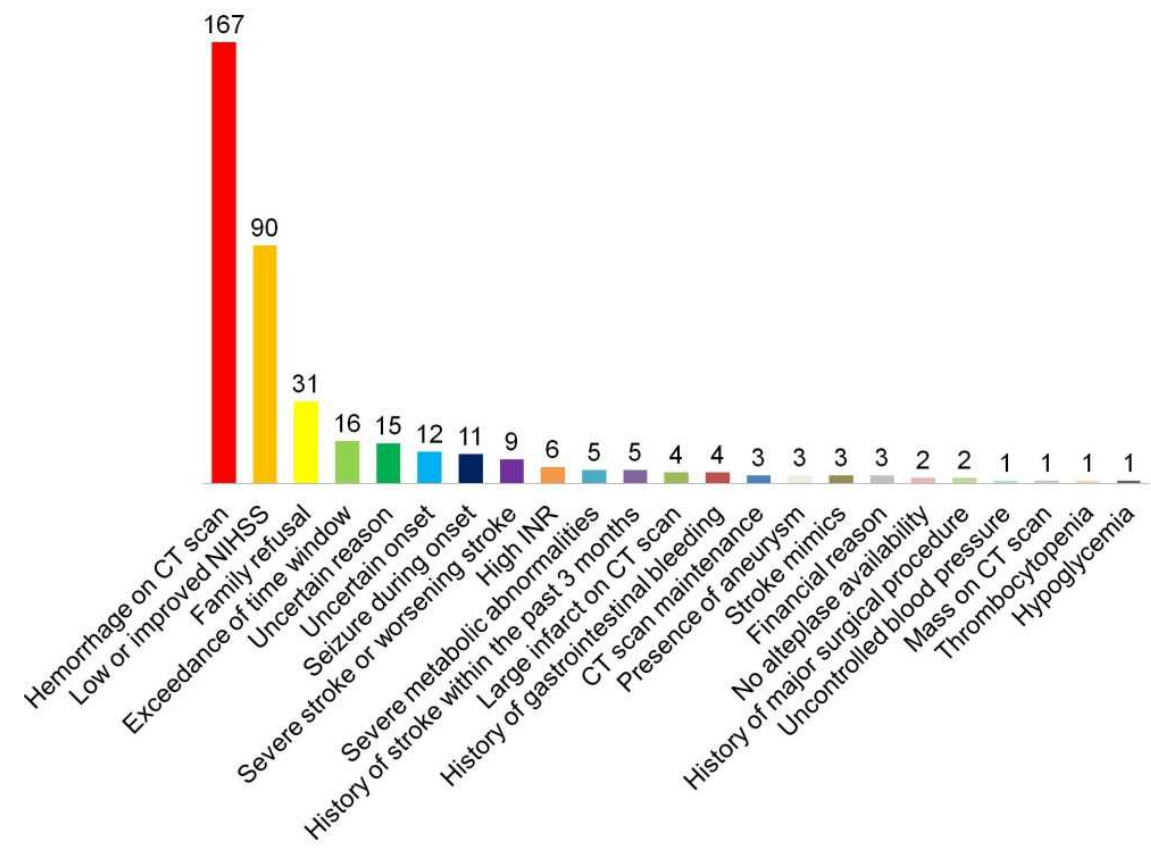

Fig. 1: Reasons acute stroke patients did not receive thrombolysis, CT scan: computed tomography scan, NIHSS: National Institutes of Health Stroke Scale, INR: international normalized ratio

\section{DISCUSSION}

Intravenous tissue plasminogen activator (IV tPA) use has increased over the past decade as the primary treatment for the management of acute ischemic stroke $[4,6]$. However, approximately one-third of eligible patients did not receive IV tPA due to various reasons $[7,8]$. Messé stated that up to 1 out of 5 potentially eligible patients did not receive treatment with IV tPA [4]. In this study, 76.3\% of acute stroke patients did not receive thrombolysis $(\mathrm{n}=395)$. This finding corresponded with $\mathrm{Hu}$ et al. study found that only $22.6 \%$ of acute ischemic stroke patients arrived at the hospital within $2 \mathrm{~h}$ of stroke onset received intravenous thrombolysis [6].

In this study, it was found that hemorrhage on computed tomography (CT) scan was the most common reason patients did not receive thrombolytic therapy (42.3\%). This finding corresponded with Fugate and Rabinstein stated that intracranial hemorrhage was one of the factors limiting the eligibility of acute 
ischemic stroke patients in receiving IV tPA, as well as recent gastrointestinal bleeding, thrombocytopenia, and coagulopathies [9]. In Pidaparthi et al. study, hemorrhagic infarct was one of the unavoidable factors for nonadministration of thrombolysis in ischemic stroke patients alongside massive infarct, gastrointestinal bleed, oral anticoagulant usage with prolonged international normalized ratio (INR), and recent cataract surgery [10]. Any kind of hemorrhage is a contraindication for thrombolytic therapy. In Messé study, percentage of CT findings for intracerebral hemorrhage (ICH), subarachnoid hemorrhage ( $\mathrm{SAH})$, and infarct as a contraindication of IV tPA was 5.3\% [4]. Prevalence of hemorrhagic stroke in Indonesia is still quite high. In Yudiarto et al. study, prevalence of hemorrhagic stroke gathered from 11 hospitals in Indonesia was $32.9 \%$ [2]. In 2018, Harris et al. performed study of 18 hospitals in Indonesia conducted using Stroke Case Report Form from 2012 to 2014 . Out of 5411 patients, $3627(67.03 \%)$ had ischemic stroke and $1784(32.97 \%)$ had hemorrhagic stroke [1]. Hypertension was the most common risk factor for hemorrhagic stroke (71.2\%) and ischemic stroke $(63.4 \%)$ [2, 11]. ICH accounts for approximately 10$20 \%$ of all strokes [12, 13]. One of risk factors for ICH is hypertension [14]. Prevalence of hypertension in Indonesia based on measurement was $34.1 \%$ according to Indonesia Basic Health Research 2018 (Riset Kesehatan Dasar/RISKESDAS 2018), which was still quite high [15]. Furthermore, Cipto Mangunkusumo General Hospital is the national referral center hospital of Indonesia. It is the top referral hospital of the health referral system in Indonesia. This hospital receives complicated or end-stage patients that cannot be treated in other hospitals anymore. This could be another reason explaining why percentage of hemorrhagic stroke patients in this hospital-obtained from this study-was high.

The second most common reason patients did not receive thrombolysis was low or improved National Institutes of Health Stroke Scale (NIHSS) score (22.8\%). This finding corresponded with finding from Messé et al. and Nalleballe et al. study. Messé et al. study found that rapidly improving or mild stroke was the most common reason patients failed to have thrombolysis performed (51.4\%) [4]. Nalleballe et al. study found that minimal deficits were the most common reason acute stroke patients did not treated with IV tPA in 2015 and 2016, with percentage $42.17 \%$ and $49.5 \%$, respectively [16]. In $\mathrm{Hu}$ et al. study, mild or rapidly improving symptoms was the third most common reason (9\%) [6]. Khatri et al.' analysis on the National Institute of Neurological Disorders and Stroke (NINDS) tPA Trials found a significant number of patients with minimal deficit excluded from the trials [17]. This raised the validity of excluding patients with minimal deficit from receiving IV tPA.

Total of 31 patients (7.8\%) did not receive thrombolytic therapy due to family refusal. This finding corresponded with Nallebelle et al. study found that patients or next to kin refusal were the third most common reason patients failed to receive IV tPA in 2015 and 2016, with percentage $18.02 \%$ and $16.50 \%$, respectively [16]. In $\mathrm{Hu}$ et al. study, patient or family refusal was the reason $74 \%$ patients failed to receive thrombolytic therapy [6]. This showed that education about etiology, symptoms, and treatment of stroke to enhance patients' family knowledge and awareness of the impact of treatment refusal needs to be improved to achieve good outcomes of the patients. Possibility of communication barrier existence also needs to be investigated. Most patients' family refused thrombolysis to be given to the patients due to a chance of bleeding risk following the thrombolytic therapy. For financial problems, thrombolysis cost in Cipto Mangunkusumo General Hospital is free because there is a National Health Insurance in Indonesia that provides financial insurance to all of residents in Indonesia.

Exceedance of time window was the next most common reason, with a percentage $4.1 \%$. Patients presented to the hospital outside of the time window continued to be an obstacle for IV tPA administration [18-21]. In Nallebelle et al. study, exceedance of time window was the second most common reason acute stroke patients did not receive IV tPA in 2015 and 2016 (22.44\% and 22\%, respectively) [16]. Code Stroke has been developed to minimize delay in thrombolysis administration [22]. Cipto Mangunkusumo General Hospital has extended onset-to-door time up to $6 \mathrm{~h}$. However, time window exceedance still became one of the most common reasons limiting the eligibility of patients to receive thrombolytic therapy. Knowledge regarding symptoms and treatment of stroke needs to be enhanced among the society-Indonesian society in this matter-to prevent this delay.

Our study had a few limitations. There was no follow-up available for final diagnosis confirmation of patients who did not receive thrombolytic therapy.

\section{CONCLUSION}

Results of this study showed that hemorrhage on computed tomography (CT) scan was the most common reason patients did not receive thrombolytic therapy. Intracranial hemorrhage is a contraindication for thrombolytic therapy. Prevalence of hemorrhagic stroke in Indonesia is still quite high. The next most common reasons were low or improved National Institutes of Health Stroke Scale (NIHSS) score, family refusal, and exceedance of the time window.

\section{ACKNOWLEDGMENTS}

The authors would like to thank all the party involved in the working of this study.

\section{AUTHORS CONTRIBUTIONS}

All the authors have contributed equally

\section{CONFLICT OF INTERESTS}

The authors have no potential conflict of interest to disclose

\section{REFERENCES}

1. Harris S, Kurniawan M, Rasyid A, Mesiano T, Hidayat R Cerebral small vessel disease in Indonesia: lacunar infarction study from Indonesian stroke registry 2012-2014. SAGE Open Med 2018;6:2050312118784312.

2. Yudiarto F, Machfoed MH, Amir D, Ong A, Kurniawan M, Siswanto $\mathrm{S}$, et al. Hypertension is the most risk factor stroke in Indonesia Stroke Registry. Neurology 2017;88 Suppl 16:P3,263.

3. Kurniawan M, Zairinal RA, Mesiano T, Hidayat R, Harris S, Ranakusuma TA. Terapi trombolisis intravena pada pasien stroke iskemik dengan awitan kurang dari 6 jam. Neurona 2014;32. Available from: http://www.neurona.web.id/paperdetail.do?id=913. [Last accessed on 20 May 2019]

4. Messe SR, Khatri P, Reeves MJ, Smith EE, Saver JL, Bhatt DL, et al. Why are acute ischemic stroke patients not receiving IV tPA? Results from a national registry. Neurology 2016;87:1565-74.

5. Wang Y, Liao X, Zhao X, Wang DZ, Wang C, Nguyen Huynh MN, et al. Using recombinant tissue plasminogen activator to treat acute ischemic stroke in China: analysis of the results from the Chinese National Stroke Registry (CNSR). Stroke 2011;42:1658-64.

6. Hu Z, Chen $\mathrm{C}$, Zeng L, Changsha. The most common reasons for acute ischemic stroke patients not receiving IV tPA in China. 2019. Available from: https://n.neurology.org/content/mostcommon-reasons-acute-ischemic-stroke-patients-notreceiving-iv-tpa-china. [Last accessed on 21 May 2019]

7. Adeoye $\mathrm{O}$, Hornung $\mathrm{R}$, Khatri P, Kleindorfer D. Recombinant tissue-type plasminogen activator use for ischemic stroke in the United States: a doubling of treatment rates over the course of 5 y. Stroke 2011;42:1952-5.

8. Schwamm LH, Ali SF, Reeves MJ, Smith EE, Saver JL, Messe S, et al. Temporal trends in patient characteristics and treatment with intravenous thrombolysis among acute ischemic stroke patients at get with the guidelines-stroke hospitals. Circ Cardiovasc Qual Outcomes 2013;6:543-9.

9. Fugate JE, Rabinstein AA. Absolute and relative contraindications to IV rt-PA for acute ischemic stroke. Neurohospitalist 2015;5:110-21.

10. Pidaparthi L, Kotha A, Aleti VR, Kohat AK, Kandadai MR, Turaga $\mathrm{S}$, et al. Factors influencing nonadministration of thrombolytic therapy in early arrival strokes in a university hospital in Hyderabad, India. Ann Indian Acad Neurol 2016;19:351-5.

11. Venketasubramanian N, Yoon BW, Pandian J, Navarro JC. Stroke epidemiology in South, East, and South-East Asia: a review. J Stroke 2017;19:286-94. 
12. Feigin VL, Lawes CM, Bennett DA, Barker-Collo SL, Parag V. Worldwide stroke incidence and early case fatality reported in 56 population-based studies: a systematic review. Lancet Neurol 2009;8:355-69.

13. Sacco S, Marini C, Toni D, Olivieri L, Carolei A. Incidence and 10 -year survival of intracerebral hemorrhage in a populationbased registry. Stroke 2009;40:394-9.

14. An SJ, Kim TJ, Yoon BW. Epidemiology, risk factors, and clinical features of intracerebral hemorrhage: an update. J Stroke 2017;19:3-10.

15. Badan Penelitian dan Pengembangan Kesehatan. Hasil Riskesdas. Badan Penelitian dan Pengembangan Kesehatan; 2018.

16. Nalleballe K, Sharma R, Kovvuru S, Brown A, Sheng S, Gundapaneni $\mathrm{S}$, et al. Why are acute ischemic stroke patients not receiving thrombolysis in a telestroke network? J Telemed Telecare 2019;1357633X18824518.

17. Khatri P, Tayama D, Cohen G, Lindley RI, Wardlaw JM, Yeatts $\mathrm{SD}$, et al. Effect of intravenous recombinant tissue-type plasminogen activator in patients with mild stroke in the third international stroke trial-3: post hoc analysis. Stroke 2015;46:2325-7.

18. Fang MC, Cutler DM, Rosen AB. Trends in thrombolytic use for ischemic stroke in the United States. J Hosp Med 2010;5:406-9.

19. Barber PA, Zhang J, Demchuk AM, Hill MD, Buchan AM. Why are stroke patients excluded from TPA therapy?: an analysis of patient eligibility. Neurology 2001;56:1015-20.

20. Garcia Monco JC, Pinedo A, Escalza I, Ferreira E, Foncea N, Gomez Beldarrain $\mathrm{M}$, et al. Analysis of the reasons for exclusion from tPA therapy after early arrival in acute stroke patients. Clin Neurol Neurosurg 2007;109:50-3.

21. Bunch ME, Nunziato EC, Labovitz DL. Barriers to the use of intravenous tissue plasminogen activator for in-hospital strokes. J Stroke Cerebrovasc Dis 2012;21:808-11.

22. Rasyid A, Harris S, Nurhayati E, Prihartono J. Pentoxifylline in acute ischemic stroke patients with blood hyperviscosity. Int J Appl Pharm 2018;10:307-10. 